\title{
Attitudes and barriers of medical students towards conducting research in a medical college
}

\author{
Manjunath G. Narasimhaiah ${ }^{1 *}$, Swamy R. Mallikarjuna1 ${ }^{1}$, Riyaj A. Kalaburgi ${ }^{2}$
}

${ }^{1}$ Department of Pharmacology, Sri Siddhartha Medical College, Tumkur, Karnataka, India

${ }^{2}$ Department of Community Medicine, Sri Siddhartha Medical College, Tumkur, Karnataka, India

Received: 15 April 2020

Revised: 11 May 2020

Accepted: 12 May 2020

\section{* Correspondence:}

Dr. Manjunath G. Narasimhaiah,

Email: manjunathpharmacology@gmail.com

Copyright: (c) the author(s), publisher and licensee Medip Academy. This is an open-access article distributed under the terms of the Creative Commons Attribution Non-Commercial License, which permits unrestricted non-commercial use, distribution, and reproduction in any medium, provided the original work is properly cited.

\begin{abstract}
Background: It is well known that evidence-based medicine is the rule for clinical practice. This can be enhanced by conducting good research. Medical students being the future doctors should contribute significantly. But the research among the medical students is very poor with respect to presentations and publications. In view of this data the study was done to know their perception, attitude and barriers for conducting research.

Methods: This was a cross sectional observational study involving three different batches of medical students by giving a semi-structured questionnaire.

Results: The response among the participants to involve in research was only $30 \%$. Among them the overall attitude and barrier score were $3.69 \pm 0.29$ and $3.63 \pm 0.42$ respectively with statistical significance shown between genders and not between batches. The biggest barrier was lack of previous research experience (91.67\%). The most common motivational factor was self-interest $(90.7 \%)$.

Conclusions: If given sufficient training and facilities provided, we should be able to get more research among the medical students.
\end{abstract}

Keywords: Attitudes, Barriers, Motivational factors, Student research

\section{INTRODUCTION}

Scientific research is a systematic study aiming to solve a problem and is the main stimulus in a society to guarantee its development and is considered a key growth indicator. The difference between the developed and developing countries lies in the research facilities, conditions, and domains. ${ }^{1}$ The concern toward scientific research has increased in both developing and developed countries because biomedical research can improve medical care. ${ }^{2}$ In fact, developing countries do not use research instruments to recognize and solve problems and that is why they are incapable of meeting their needs scientifically. Therefore, developing countries are mainly consumers of the scientific findings of the developed countries, mostly published in the academic journals of the same countries. As universities are the main scientific core of the societies, it is the duty of the universities to perform a great portion of the research works. ${ }^{1}$ The medical students should be aware of the methods in carrying out research as they will be future doctors who will have to practice evidence-based medicine in patient care. $^{2}$

Research in medicine has an impact on prevention, diagnosis, and newer treatment for the medical ailments. It has brought reforms in policies for health-care programs. $^{2}$ All undergraduate students in all higher education institutions should experience learning through, and about, research and inquiry. For this to be possible it 
can only occur if the experiences are integrated into the curriculum (Jenkins and Healey 2012). ${ }^{3}$ The new CBME curriculum has brought in the research culture by making it mandatory as electives. The vast curriculum of MBBS makes them averted towards conduct of research. Approximately 1500 students (1200 seats - MBBS and 300 seats - BDS) will be awarded short term studentship in January 2021 after the report submission and review for the year $2020 .^{4}$

Literature review shows that inadequate knowledge and skills of research methodology, limited access to information sources, lack of time and mentoring, academic preference and financial constraints were the barriers for conducting research. ${ }^{1-6}$ Attitude was also below the average line. ${ }^{6}$ Majority of the studies on this are conducted among the faculties and overseas. Hence this study was initiated to identify the various barriers, motivational factors and attitude to conduct research.

\section{METHODS}

This was a cross sectional observational study which was conducted on medical students of Siddhartha Academy of Higher Education across various batches of MBBS. The study was conducted from February to April 2020 after taking prior approval from the institutional ethics committee. Inclusion criteria include all students of either sex, different batches of MBBS and who are willing to participate in this study. $1^{\text {st }}$ MBBS students were excluded from this study. The questionnaire was selfdesigned after literature search and relevance was verified by the colleagues. The ability to understand was checked by administering the questionnaire to few undergraduate students as pilot study. The questions were modified according to the suggestions. The reliability coefficient was accessed by Cronbach alpha which was 0.707 for attitude and 0.513 for barrier.

This semi-structured questionnaire consists of 4 parts. Part one includes demographic data like age, gender and batch. Part 2 contains attitude questions in the 5 points scale of strongly agree (SA) with score 5, agree (A) with score 4, neutral (N) with score 3, disagree (DA) with score 2 and strongly disagree (SD) with score 1 format. Part 3 contains questions regarding the motivational factors for conducting research. Lastly, part 4 contains various barriers for conducting research. This questionnaire was distributed during the lockdown period of Covid 19 pandemic through electronic media. The questionnaire was shared in all 3 batches $\left(2^{\text {nd }}, 3^{\text {rd }}\right.$ and final year) of medical students consisting of 360 students. Only completed questionnaire was used for analysis. The data obtained out of this was entered in excel sheet and analysed using statistical software.

\section{RESULTS}

The total response rate in this study was only $30 \%$ (108/360) with males contributing to $47.2 \%$ and females $52.8 \%$. The mean age of the participants was $21.35 \pm 1.87$ among males and $20.98 \pm 1.26$ among females. Majority of the participants were from $2^{\text {nd }}$ year $(41.7 \%)$ (Table 1$)$.

Table 1: General characteristics of the study participants.

\begin{tabular}{|llll|}
\hline Characteristics & Frequency & $\%$ & $\begin{array}{c}\text { Mean age } \\
\text { (in years) }\end{array}$ \\
\hline Study year & & & \\
\hline $2^{\text {nd }}$ & 45 & 41.7 & $20.09 \pm 0.82$ \\
\hline $3^{\text {rd }}$ & 32 & 29.6 & $21.16 \pm 0.92$ \\
\hline $4^{\text {th }}$ & 31 & 28.7 & $22.71 \pm 1.53$ \\
\hline Sex & & & \\
\hline Male & 51 & 47.2 & $21.35 \pm 1.87$ \\
\hline Female & 57 & 52.8 & $20.98 \pm 1.26$ \\
\hline Total & 108 & 100.0 & $21.16 \pm 1.53$ \\
\hline
\end{tabular}

The average attitude score and barrier score between the genders were $3.69 \pm 0.29(\mathrm{p}=0.463)$ and $3.63 \pm 0.42(\mathrm{p}=$ 0.013 ) respectively (Table 2 ).

However, there was not much difference in attitude and barrier score between the different batches of participants.

Analysis of attitude of participants' shows that majority of the participants have a positive attitude either by agreeing or strongly agreeing as shown in (Figure 1).

Similarly, analysis was done for the various barriers in conducting research as shown in (Figure 2). The biggest barrier identified was no previous research experience $(91.67 \%)$ and the least identified barrier was lack of encouragement from the faculty $(25 \%)$. The motivational factors for getting involved in research as opined by participants were their own interest $(90.7 \%)$, favour in academic performance $(54.6 \%)$, presenting in scientific forum $(53.7 \%)$ and facilitate foreign competitive examinations $(40.7 \%)$.

Table 2: Comparison of attitude scores and barrier scores between males and female participants.

\begin{tabular}{|c|c|c|c|c|c|c|}
\hline Score & Sex & $\mathbf{N}$ & Mean & SD & t value & P value \\
\hline \multirow{3}{*}{ Average attitude score } & Male & 51 & 3.63 & 0.31 & \multirow{3}{*}{-0.737} & \multirow{3}{*}{0.463} \\
\hline & Female & 57 & 3.67 & 0.28 & & \\
\hline & Total & 108 & 3.65 & 0.29 & & \\
\hline \multirow{3}{*}{ Average barrier score } & Male & 51 & 3.74 & 0.38 & \multirow{3}{*}{2.538} & \multirow{3}{*}{0.013} \\
\hline & Female & 57 & 3.54 & 0.43 & & \\
\hline & Total & 108 & 3.63 & 0.42 & & \\
\hline
\end{tabular}




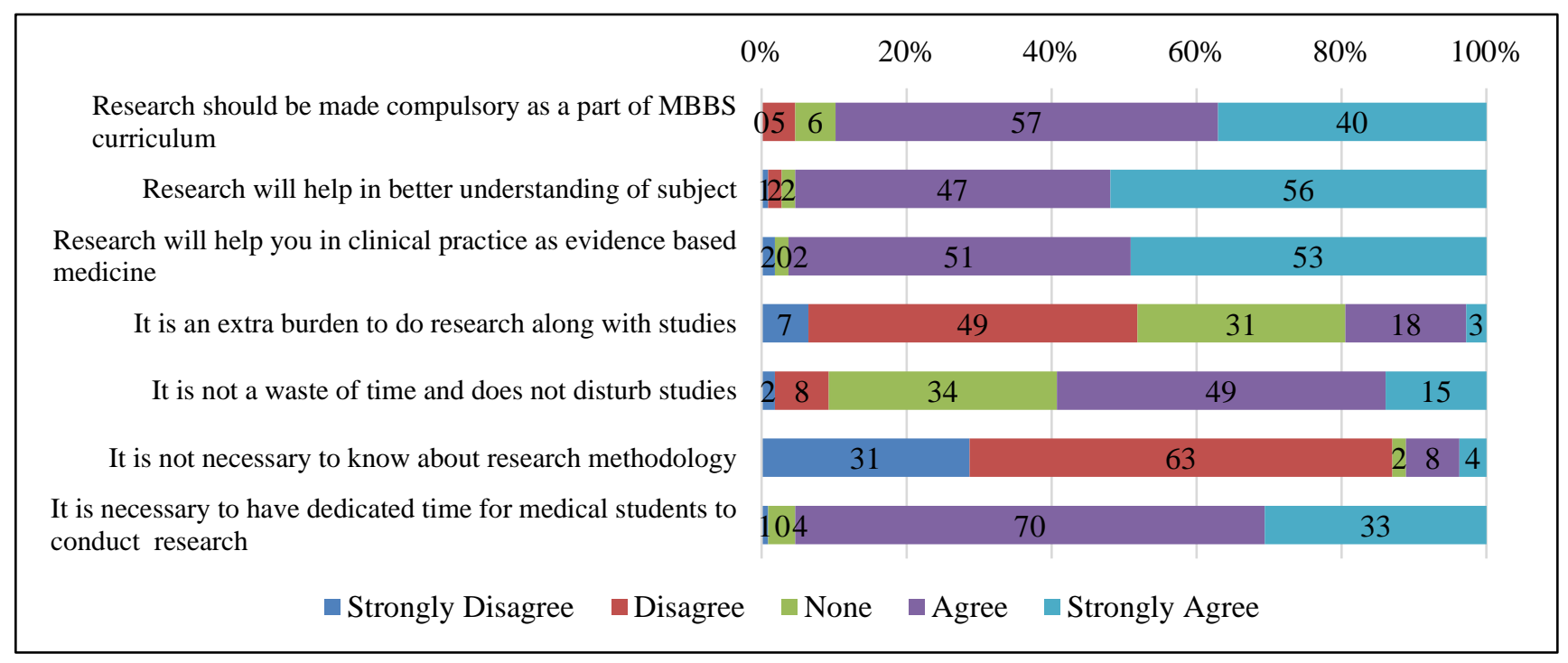

Figure 1: Attitude of participants in conducting research.

There is Lack of infrastructure

There is No previous research experience

It is Difficult to follow patients/participants

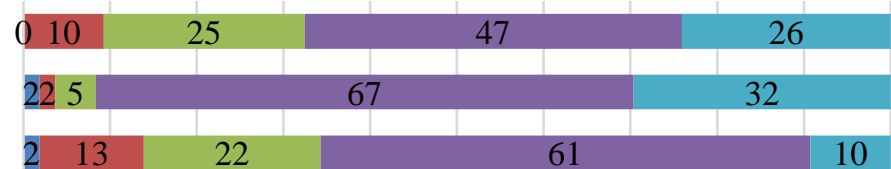

There is Lack of sufficient time for research

There is Lack of encouragement from faculty

There is No funding for research

There is Lack of self interest

There is a Lack of skill and knowledge on research

There is lack of incentive

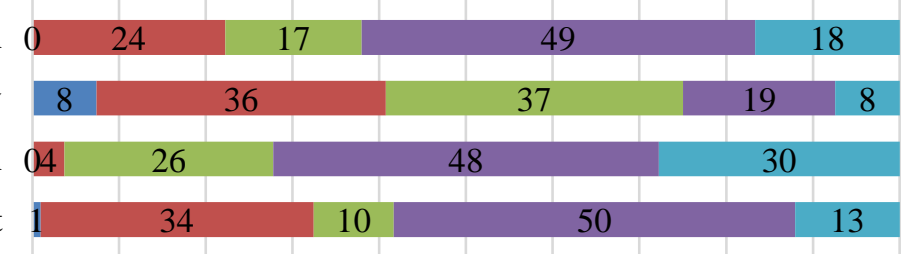

\begin{tabular}{|l|l|l|l|l|l|}
\hline 2 & 17 & 13 & 61 & 15 \\
\hline 0 & 13 & 18 & 64 & 13 \\
\hline
\end{tabular}

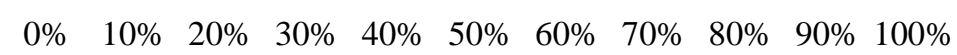

$\square$ Strongly Disagree $\quad$ Disagree $\quad$ None $\quad$ Agree $\square$ Strongly Agree

Figure 2: Barriers in conducting research.

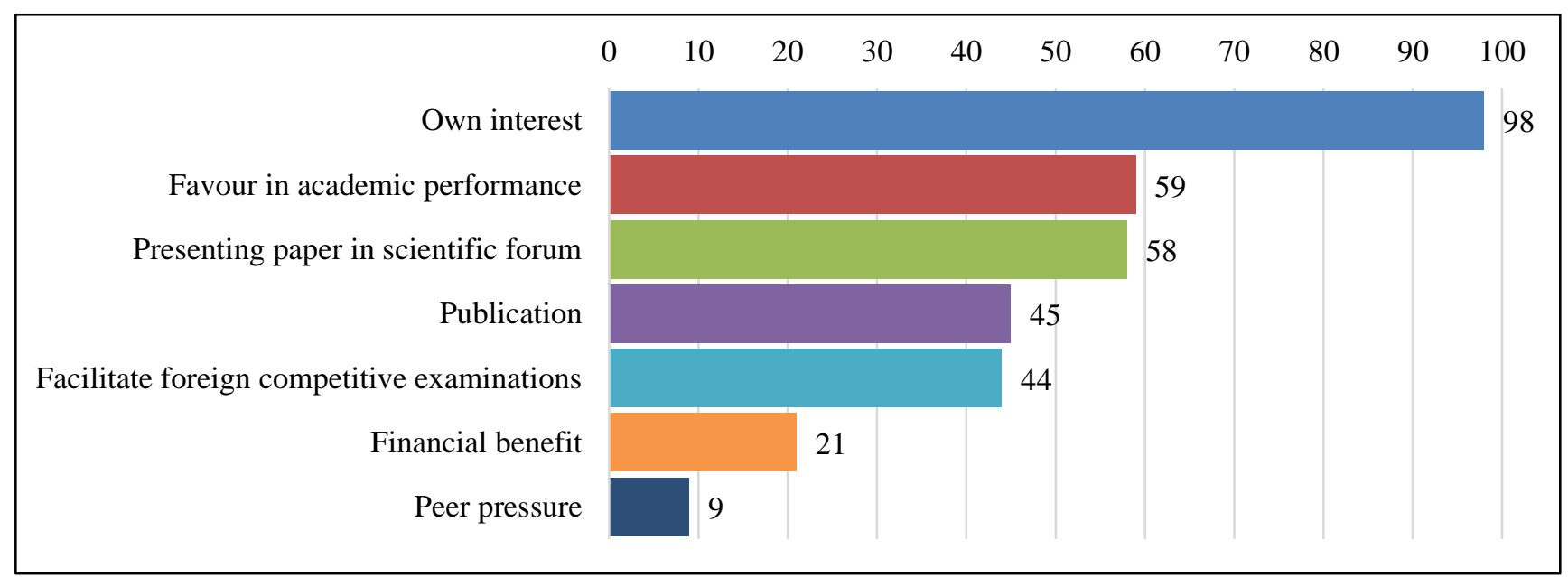

Figure 3: Motivations required in conducting research. 
The least motivational factors were peer pressure $(8.3 \%)$ and financial benefit (19.4\%) (Figure 3).

Apart from these factors, hands on experience, knowledge, social cause and strong support from university were other factors specified.

\section{DISCUSSION}

Although, the importance of research is well known and repeatedly stated in the field of medicine, only a small proportion of medical students conduct research. ${ }^{7,8}$ To carry out a research adequate knowledge, a positive attitude and acceptable skills are required. ${ }^{9,10}$ There are many factors and barriers that are responsible for this deficit in conducting research.

In this study it was seen that only small percentage $(30 \%)$ of students showed interest to participate in this study indicating the poor attitude or not well versed with conduct of research. The participants who submitted the survey only were analysed. The attitude score of the students was similar even with the advancement of their academic year with not much statistical significance but was better in $3^{\text {rd }}$ years students in a study conducted in Kolar. ${ }^{2,11-13}$ In another study there was a decline during progressive indicating more importance for the academics than research. ${ }^{14}$ There is a MCI guideline to have a compulsory presentation and publications at post graduate level but nothing as such in undergraduate level. $^{2}$ As a result of this, there is a decrease in presentations and publications by the undergraduate medical students. However, the present CBME curriculum has brought in a change by adding electives in the $3^{\text {rd }}$ year to conduct research is a positive hope.

We tried to identify certain barriers also for conducting research. Among them lack of prior experience (91.67\%) was one the major barrier which can be addressed by giving sufficient training. Lack of funding (72.22\%), lack of incentive $(71.3 \%)$ and lack of skill and knowledge $(70.37 \%)$ were the other major barriers contributing to poor research which were similar to other study conducted elsewhere. ${ }^{1,7,15-18}$ In contrast to this study lack of time and mentoring were the other factors in a study conducted by Kumar et al. ${ }^{5}$ Lack of self-interest and difficult to follow the participants were the other factors. There is sufficient encouragement from the faculty as opined by the participants. If any motivation has to be there to conduct research it is only the Own interest which has been agreed by most of the participants $(90.7 \%)$. The second most factors were some favour in their academic performance $(54.6 \%)$ and to give presentation in scientific forum $(53.7 \%)$ as the third factor. The participant's do not have much peer pressure to conduct research.

The number of studies conducted among the medical students regarding the perception, attitude and barriers of conducting research is very poor. With the introduction of electives in the new MBBS curriculum might take forward the situation into different level. To reach this state we need the teachers also to get trained so that they can guide the students. Sufficient knowledge and training regarding research methodology should be inculcated in the curriculum which also opined by the participants. As of now the only motive is the short-term studentship program by ICMR which encourages students to conduct research.

The lacunae identified with respect to the barriers needs to be addressed and students should be motivated sufficient enough to conduct research.

\section{CONCLUSION}

One of the most important points identified in this study is the poor interest in being a participant of research. Females had a better attitude in conducting research compared to males and there was not much a difference among the different batches of MBBS students. The biggest barrier identified was lack of previous research experience. Encouragement by faculty was adequate as opined by the participants. If we can provide adequate motivation and attend to the barriers, research culture by students can be enhanced.

\section{ACKNOWLEDGEMENTS}

MBBS students of Sri Siddhartha Medical College, SAHE, Tumkur.

Funding: No funding sources

Conflict of interest: None declared

Ethical approval: The study was approved by the Institutional Ethics Committee

\section{REFERENCES}

1. Dadipoor S, Ramezankhani A, Aghamolaei T, Moradabadi SA. Barriers to research activities as perceived by medical university students: A crosssectional study. Avicenna J Med. 2019;9(1):8-14.

2. Pallamparthy S, Basavareddy A. Knowledge, attitude, practice, and barriers toward research among medical students: a cross-sectional questionnairebased survey. Perspect Clin Res. 2019;10(2):73-8.

3. Students as researchers: supporting undergraduate research in the disciplines in higher education Available at: https://www.heacademy.ac.uk/system/ files/resources/Students\%20as\%20researchers_1.pdf. Accessed on 11 March 2020.

4. ICMR short term studentship for 2020. Available at: http://14.139.60.56:84/Homepage.aspx. Accessed on 12 March 2020.

5. Kumar J, Memon A, Kumar A. Barriers Experienced by Medical Students in Conducting Research at Undergraduate Level. Cureus. 2019;11(4):4452.

6. Memarpour M, Fard AP, Ghasemi R. Evaluation of attitude to, knowledge of and barriers toward 
research among medical science students. Asia Pacific Family Med. 2015;14:1.

7. Alghamdi KM, Moussa NA, Alessa DS, Alothimeen N, Saud AS. Perceptions, attitudes and practices toward research among senior medical students. Saudi Pharm J. 2014;22:113-7.

8. Siemens DR, Punnen S, Wong J, Kanji N. A survey on the attitudes towards research in medical school. BMC Med Educ. 2010;10:4.

9. Pawar DB, Gawde SR, Marathe PA. Awareness about medical research among resident doctors in a tertiary care hospital: a cross-sectional survey. Perspect Clin Res. 2012;3:57-61.

10. Siamian H, Mahmoudi R, Habibi F, Latifi M, Gavgani ZV. Students attitudes towards research at Mazandaran University of medical sciences in 2015. Mater Socio Med. 2016;28:468-72.

11. Noorelahi MM, Soubhanneyaz AA, Kasim KA. Perceptions, barriers, and practices of medical research among students at Taibah College of Medicine, Madinah, Saudi Arabia. Adv Med Educ Pract. 2015;6:479-85.

12. Siamian H, Mahmoudi R, Habibi F, Latifi M, Gavgani ZV. Students attitudes towards research at Mazandaran University of medical sciences in 2015. Mater Socio Med. 2016;28:468-72.

13. Nel D, Burman RJ, Hoffman R, Rees RS. The attitudes of medical students to research. S Afr Med J. 2013;104:33-6.
14. Osman T. Medical students perceptions towards research at a Sudanese University. BMC Med Educ. 2016;16:253.

15. Amin T, Kaliyadan F, Abdulatheem EA, Majed M, Khanjaf H, Mirza M. Knowledge, attitudes and barriers related to participation of medical students in research in three Arab Universities. Educ Med J. 2012;4:47-55.

16. Burgoyne LN, Flynn OS, Boylan GB. Undergraduate medical research: The student perspective. Med Educ Online. 2010;15:1-9.

17. Sabzwari S, Kauser S, Khuwaja AK. Experiences, attitudes and barriers towards research amongst junior faculty of Pakistani medical universities. BMC Med Educ. 2009;9:68.

18. Mowla A, Nabavizadeh SA, Bajestan MN, Tavakoli A, Seifi A, Tavakoli A, et al. Payment as motivator in Iranian medical students' attitudes toward research. South Med J. 2006;99:1403.

Cite this article as: Narasimhaiah MG, Mallikarjuna SR, Kalaburgi RA. Attitudes and barriers of medical students towards conducting research in a medical college. Int J Basic Clin Pharmacol 2020;9:966-70. 